Premiere Educandum: Jurnal Pendidikan Dasar dan Pembelajaran

Volume 8(1) 15 - 21 Juni 2018

Copyright (C2018 Universitas PGRI Madiun

ISSN: 2088-5350 (Print) / ISSN: 2528-5173 (Online)

Available at: http://e-journal.unipma.ac.id/index.php/PE

Doi: $10.25273 /$ pe.v8i1.1832

\title{
Membangun virtual classroom melalui social learning networks (SLNS)
}

\author{
Eliya Rochmah ${ }^{1)}$, Nuur Wachid Abdulmajid ${ }^{2)}$ \\ ${ }^{1}$ Fakultas Keguruan dan Ilmu Pendidikan, Universitas Muhammadiyah Cirebon \\ 1email: eliya.rochmah@umc.ac.id \\ ${ }^{2}$ Universitas Pendidikan Indonesia Kampus Purwakarta \\ 2email: nuurwachid@upi.edu
}

\begin{abstract}
The development of technology has affected all aspects of life, one of which is the aspect of education. Conventionally, the process of teaching and learning is identical with the face-to-face meetings. However, in the era of the development of this technology, there is a change of paradigm by using the help of technology, one of them is Social Learning Networks (SLNs). This article will discuss with regards to Social Learning Networks (SLNs) that can be used for learning. So the formation of civil society by developing the information technology in education can be realized
\end{abstract}

Keywords: SLNs, social learning network, virtual classroom, online learning.

\section{Abstrak}

Perkembangan teknologi telah mempengaruhi ke segala aspek kehidupan salah satunya adalah aspek pendidikan. Secara konvensional, proses belajar mengajar identik dengan adanya pertemuan tatap muka. Namun pada era perkembangan teknologi ini terdapat perubahan paradigma dengan menggunakan bantuan teknologi, salah satunya adalah Sosial Learning Networks (SLNs). Artikel ini akan membahas berkaitan dengan Sosial Learning Networks (SLNs) yang dapat dimanfaatkan untuk pembelajaran. Sehingga terbentuknya masyarakat madani dengan mengembangkan teknologi informasi dalam pendidikan dapat terwujud.

Kata kunci: SLNs, social learning network, virtual classroom, pembelajaran online.

Histori artikel : disubmit pada 13 November 2017; direvisi pada 24 Januari 2018; diterima pada 29 Januari 2018

\section{A. PENDAHULUAN}

Masyarakat madani adalah masyarakat yang beradab, menjunjung tinggi nilai-nilai kemanusiaan, yang maju dalam penguasaan ilmu pengetahuan, dan teknologi. Sebagai pelaku pendidikan, sudah selayaknya menunjukkan kepribadian sebagai masyarakat madani salah satunya dengan mengikuti perkembangan teknologi. Perkembangan teknologi telah mempengaruhi ke segala aspek kehidupan salah satunya adalah aspek pendidikan. Teknologi telah mengubah proses belajar mengajar dari konvensional menjadi proses belajar yang terintegrasi dengan teknologi. Guru mempunyai peran yang strategis untuk meningkatkan prestasi belajar siswa melalui proses belajar (Eliya, 2015). Guru dapat memanfaatkan internet untuk mencari bahan terbaru atau informasi berkaitan dengan pelajaran yang akan 
diajarkan kepada siswa (Abdulmajid, N.W. \& Setiadi, B.R., 2015).

Secara konvensional, proses belajar mengajar identik dengan adanya pertemuan tatap muka (face to face) antara guru dan siswa yang berlangsung di dalam kelas. Guru akan memberi materi dan siswa menjadi subyek penerima materi. Interaksi antara guru dan siswa pun terjadi secara langsung. Apabila guru berhalangan hadir di kelas maka proses pembelajaran akan terhambat. Padahal dengan adanya perkembangan teknologi saat ini, konsep pembelajaran konvensional tersebut dapat diubah menjadi proses pembelajaran yang tidak hanya fokus terhadap guru. Proses pembelajaran yang konvensional dapat diubah menjadi proses pembelajaran dengan menggunakan teknologi salah satunya adalah Sosial Learning Networks (SLNS).

Melalui SLNs, proses pembelajaran dapat berlangsung di mana pun juga. Guru dan siswa, dosen dan mahasiswa, tutor dan tutee (peserta tutorial) tidak perlu lagi bertemu tatap muka di dalam ruang kuliah. SLNs memungkinkan guru dan siswa menciptakan proses belajar mengajar secara virtual classroom (kelas maya). Konsep pembelajaran seperti ini dirasa lebih modern sehingga terciptalah interaksi antara guru dan siswa yang tidak terbatas ruang dan waktu.

Virtual classroom tidak sepenuhnya berbeda dengan proses belajar mengajar di kelas nyata (real classroom). Virtual classroom (kelas maya) akan membawa situasi kelas nyata ke dalam teknologi dan mengubah situasi belajar mengajar tesebut seolah-olah menjadi nyata. Dengan demikian, sangat dimungkinkan mengembangkan konsep pendidikan melalui teknologi canggih dan menghasilkan lulusan yang lebih kreatif dan produktif.

Siswa dapat menemukan pola pembelajaran yang efektif melalui pembelajaran virtual classroom. Menemukan pola untuk menyelesaikan kasus membutuhkan proses panjang dan waktu yang lama (Abdulmajid, N.W., 2016). Dengan demikian pembelajaran berbasis kasus dapat diterapkan di virtual classroom agar siswa lebih cepat dan tanggap dalam menyerap kompetensi yang diajarkan.

Perolehan kompetensi siswa juga harus didukung dengan kerjasama antar tim. Hal ini disebabkan pembelajaran secara individu terkadang membutuhkan waktu yang lama bagi siswa dalam memperoleh kompetensi. Pembentukan kompetensi siswa dan penerapannya dapat tercapai melalui konsep social partnerships, serta kompetensi yang diperoleh dapat diterapkan secara kontekstual (Majid, N.W.A \& Sudira, 2017). Dengan demikian pembelajaran secara kolaboratif dan didukung dengan virtual classroom dapat meningkatkan kemampuan siswa itu sendiri.

\section{B. METODE PENELITIAN}

Penelitian ini merupakan penelitian dan pengembangan yang mengacu pada langkah pengembangan Borg \& Gall. Pada metode penelitian ini hanya sebatas pada studi pendahuluan (konsep) yang meliputi tiga langkah awal, yaitu: (1) pengumpulan data dan informasi awal berupa observasi karakteristik mahasiswa yang sudah terbiasa dengan penggunaan notebook atau smartphone, perencanaan berupa analisis kebutuhan yang diperlukan dalam penggunaan produk seperti analisis konten mata kuliah, kebutuhan software dan hardware dan (3) pengembangan produk awal 
berupa media penunjang pembelajaran berbasis SLNs yakni Moodle. Sasaran penelitian adalah mahasiswa PGSD FKIP Universitas Muhammadiyah Cirebon. Subyek penelitian ini adalah pengkajian literatur dan situs penyedia SLNs di dunia maya.

\section{HASIL DAN PEMBAHASAN Virtual Classroom}

Virtual classroom (kelas maya) tidak sepenuhnya berbeda dengan proses belajar mengajar di kelas nyata (real classroom). Virtual classroom (kelas maya) akan membawa situasi kelas nyata ke dalam teknologi dan mengubah situasi belajar mengajar tesebut seolah-olah menjadi nyata. Kelas maya bisa diartikan kegiatan siswa dan guru untuk berkomunikasi secara bersama dengan menggunakan fitur seperti audio, video, teks chat, papan tulis interaktif, berbagi aplikasi, polling instan, emoticon, dan memakai ruangan terpisah (Florence M., 2014). Konsep pembelajaran secara virtual (maya) yakni guru dan siswa tetap bisa melakukan komunikasi secara bersama tanpa harus bertemu secara langsung.

Kelas virtual dapat membuat pembelajaran menjadi lebih efektif. Selain itu, kelas virual juga membuat kebersamaan lebih efektif untuk sisi sosial pendidikan (Motteram, 2001). Pernyataan Motteram tersebut mengindikasikan bahwa apabila media pembelajaran menciptakan susasan kebersamaan maka akan lebih efektif daripada pembelajaran yang mengedapankan fungsi masing-masing individu.

Park \& Bonk (2007) menyatakan the major benefits of using a synchronous virtual classroom as: providing immediate feedback, encouraging the exchange of multiple perspectives, enhancing dynamic interactions among participants, strengthening social presence, and fostering the exchange of emotional supports and supplying verbal elements. Artinya manfaat utama menggunakan kelas virtual yaitu memberikan umpan balik secara langsung, mendorong pertukaran berbagai pendapat, meningkatkan interaksi antara peserta didik/siswa, memperkuat sisi sosial, dan mendorong pertukaran emosional dan memasok unsur verbal.

\section{Social Learning Networks (SLNs)}

Social Network atau jejaring sosial adalah sebuah jejaring yang memuat interaksi sosial dan hubungan interpersonal. Dengan kata lain Social Network yang memungkinkan pengguna untuk dapat bertukar informasi dan saling berkomunikasi satu sama lain, memberikan komentar, saling bertukar pesan, gambar, audio dan video.

Melalui social network dapat meningkatkan hubungan interpersonal dan memfasilitasi komunikasi. Oleh karena itu social network dapat dimanfaatkan sebagai media pembelajaran. Social Netwrok yang dimanfaatkan untuk pembelajaran dikenal dengan istilah Social Learning Netwroks (SLNs). SLNs Menurut Kordesh (2000) merujuk pada koneksi interpersonal melalui interaksi dengan tujuan utama untuk pengembangan pengetahuan. Berdasarkan pernyataan tersebut berarti bahwa koneksi secara interpersonal dapat diartikan sebagai komunikasi antara guru dengan siswa, siswa dengan siswa, guru dengan orangtua, ataupun guru dengan guru. Tujuan utama adanya interaksi tersebut yaitu untuk pengembangan 
pengetahuan yakni kegiatan yang berlangsung untuk pembelajaran.

Selain itu, tujuan SLNs adalah untuk mendorong penggunanya memiliki pengalaman baru dalam belajar menggunakan jejaring sosial (Social Network) yang telah dilengkapi dengan konsep kepedulian sosial (Halimi, 2011). Pernyataan tersebut berarti bahwa SLNs tidak hanya bertujuan agar pengguna mendapatkan pengalaman baru, selain itu juga dilengkapi dengan kepedulian sosial seperti saling berkomunikasi dan berkomentar antar pengguna.

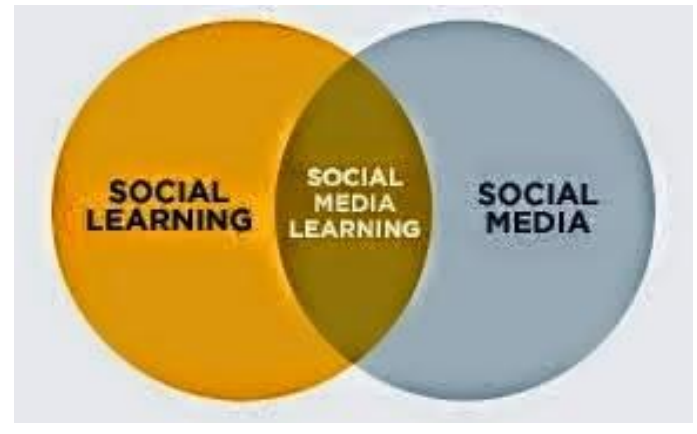

Gambar 1. Konsep Social Learning Netwroks (SLNs)

\section{Social Learning Netwroks (SLNs) menggunakan Moodle}

Moodle adalah sebuah nama untuk sebuah program aplikasi yang dapat mengubah sebuah media pembelajaran kedalam bentuk web. Aplikasi ini memungkinkan siswa untuk masuk ke dalam "ruang kelas" digital untuk mengakses materi-materi pembelajaran. Guru dan siswa dapat saling berinteraksi sehingga dapat menciptakan suasana pembelajaran yang lebih interaktif dan fleksibel. Kelebihan dari Moodle ini adalah bahwa sistem ini dapat dihubungkan dengan database mahasiswa, sehingga siswa yang mengikuti tutorial online hanya ketika mereka yang benar-benar meregistrasikan mata kuliah yang diambilnya. (Hf, 2007). Dengan menggunakan Moodle, guru dapat membuat materi pembelajaran, kuis, jurnal elektronik dan lain-lain. Beberapa gambaran mengenai Moodle adalah sebagai berikut.

1. Sederhana, ringan, efisien, dan menggunakan teknologi sederhana.

2. Mudah di Install.

3. Moodle dapat mendukung 1000 lebih pelajaran.

4. Mempunyai keamanan yang kokoh. Formulir pendaftaran untuk pelajar telah diperiksa validitasnya dan mempunyai cookies yang terenkripsi.

5. Menyediakan 45 bahasa dari seluruh dunia

Terdapat beberapa sekolah dan perguruan tinggi telah memanfaatkan fasilitas Moodle sebagai situs belajar. Salah satunya UNY dengan alamat: http://besmart.uny.ac.id/. Berikut adalah tampilan situs belajar online UNY:

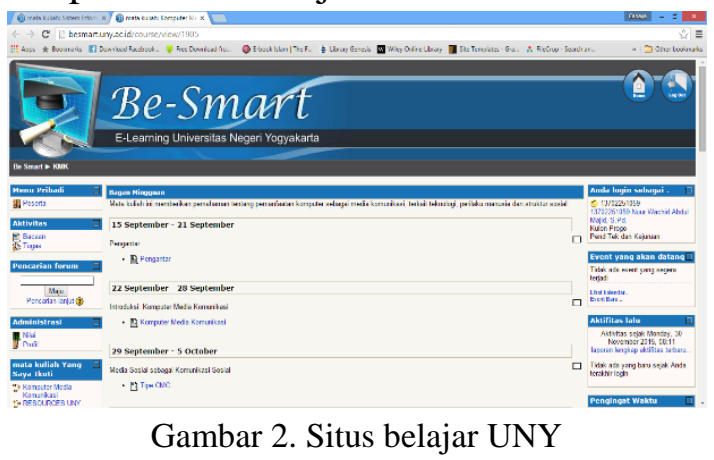

\section{Pembelajaran melalui Social Learning Networks (SLNs)}

Social Learning Networks (SLNs) sangat bermanfaat dalam meningkatkan kemampuan dan keterampilan masingmasing individu. Siswa dapat belajar sendiri (self-learning) dan melalui bimbingan. Siswa dapat menemukan hal baru dengan dituntut aktif mengikuti pembelajaran melalui SLNs. Sedangkan peran pembimbing sangat penting bagi siswa dalam menyerap ilmu yang diajarkan. Siswa dapat dengan mudah memperoleh kompetensi dari 
pembimbing tersebut, karena pembimbing mampu berbaur agar siswa mampu menerima materi dengan mudah (Abdulmajid, 2015).

Pemanfaatan SLNs dalam pembelajaran harus didukung infrastruktur teknologi. Hal ini membutuhkan seperangkat komputer dan internet agar SLNs dapat berjalan dengan baik. Guru harus menyiapkan materi yang di upload melalui SLNs sehingga siswa dapat mengakses materi tanpa adanya batasan ruang dan waktu. Materi yang di upload dapat berupa artikel atau teks, gambar, audio, video, dan beberapa bahan ajar lainnya. Moodle dan Edmodo meyediakan fasilitas kepada pengajar untuk mengupload materi. Selain itu, penugasan secara online dapat mengontrol waktu agar siswa tertib dalam pengumpulan tugas.

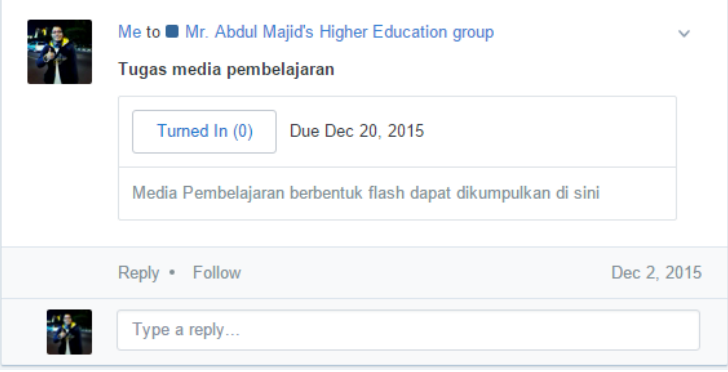

Gambar 3. Tempat pengumpulan tugas di Edmodo

Guru dan siswa dapat berinteraksi melalui fasilitas chat disediakan oleh Moodle, Edmodo, dan Google. Berinteraksi melalui fasilitas tersebut dapat dilakukan secara bersama-sama maupun secara pribadi. Sehingga guru mamp memonitor perkembangan kompetensi yang didapat oleh siswa. Guru dapat menanyakan secara langsung kepada individu ketika siswa tersebut mengalami permasalahan atau menanyakan sesuatu yang bersifat pribadi. Fasilitas chat pada dasarnya dapat meningkatkan kemampuan berkomunikasi dan berkolaborasi siswa.

Video conference menjadi pilihan alternatif apabila ingin mengundang pemateri dari luar. Hal ini dapat mengurangi anggaran dan biaya yang besar apabila akan mengundang pembicara dari luar, khususnya dari negara lain. Selain itu fasilitas ini digunakan apabila tidak memungkinkan terjadi tatap muka di kelas. Moodle menjadi salah satu pilihan untuk melakukan video conference, karena sudah terintegrasi dengan Skype dan BigBlueButton. Kedua module tersebut harus diinstal terlebih dahulu agar dapat digunakan dengan baik.

Pemanfaatan SLNs dapat meningkatkan sikap adaptasi bagi siswa terhadap perkembangan teknologi. Hal ini dikarenakan perkembangan teknologi semakin cepat, sehingga apabila siswa tidak mampu beradaptasi dengan baik dikhawatirkan terjadi ketertinggalan terhadap teknologi. Perubahan paradigma pembelajaran yang dahulu adalah teacher centered menjadi student centered, maka penggunaan teknologi dalam pembelajaran merupakan hal wajib. Siswa lebih kreatif dalam mengeksplorasi ilmu pengetahuan dan mudah beradaptasi dengan perkembangan teknologi. Dengan demikian diarapkan ketika bekerja dikemudian hari, siswa tersebut mampu beradaptasi di lingkungan kerja. Kemampuan adaptasi yang baik sangat bermanfaat bagi karyawan, karena mampu bertahan dan mengembangkan karir di tempat kerja (Majid, N.W.A, 2015) 


\section{SIMPULAN}

Berdasarkan hasil penelitian dan pembahasan dari penelitian ini, maka dapat ditarik simpulan sebagai berikut:

1. Social network dapat dimanfaatkan sebagai media pembelajaran yang sering dikenal dengan istilah Social Learning Netwroks (SLNs). SLNs bertujuan agar pengguna dapat memperoleh pengalaman baru dan meningkatkan komunikasi terhadap orang lain.

2. Social Learning Netwroks (SLNs) sudah tersedia di dunia maya, antara lain: (a) Moodle; (b) Edmodo; (c) Trello; (d) Sophia; (e) RemixLearning; (f) Schoology; dan (g) Twiducate. SLNs memiliki karakteristik yang berbeda-beda, sehingga pengguna dapat memilih SLNs yang sesuai dengan kebutuhan.

3. Social Learning Networks (SLNs) sangat bermanfaat dalam meningkatkan kemampuan dan keterampilan masing-masing individu. Sehingga pemanfaatan SLNs dalam pembelajaran harus didukung infrastruktur teknologi, seperti: seperangkat komputer dan internet.

\section{DAFTAR RUJUKAN}

Abdulmajid, N.W. (2015). Pola Pembimbingan Di Tempat Kerja: Studi Kasus Pelaksanaan Program Praktik Industri Di PT JMI. Jurnal Taman Vokasi, 3(1), 761-768.

Abdulmajid, N.W. \& Setiadi, B.R. (2015). Pemanfaatan Social Web Environment Dalam Menciptakan Student-Centered Learning dan Peningkatan Keterampilan Siswa Pada Pembelajaran. Seminar Nasional Universitas PGRI Yogyakarta. 1-6.
Abdulmajid, N.W. (2016). Kontribusi Program Praktik Industri Dalam Peningkatan Kompetensi Siswa SMK. Jurnal MEKOM, 3(1), 1-14

Adi Saputra. (2015). 5 Jejaring Sosial untuk Pembelajaran (Social Learning Network). Retrieved from http://www.oasepembelajaran.com/ 2015/02/jejaring-sosial-untukpembelajaran_86.html

Eko S. (2013). Simulasi Digital. Kementerian Pendidikan \& Kebudayaan: Jakarta

Eliya Rochmah. (2015). Pengaruh Self Regulated Learning, Gaya Belajar, dan Pola Asuh Orangtua terhadap Prestasi Belajar Mata Pelajaran Kejuruan Siswa SMK seKecamatan Weru Kabupaten Cirebon. Tesis. Universitas Negeri Yogyakarta, Yogyakarta.

Halimi, K., Seridi, H., Zucker, C.F. 2011. Solearn : Social Learning Network. International Conference and Computational Aspects of Social Network (CASoN). 130-135.

Hf. (2007). UT wajibkan mahasiswa S-1 terapkan e-learning akhir 2008. Retrieved from http://www.rrionline.com.

Kordesh. (2000). Esperanza Familiar: A University-Community Partnership as a Social Learning Network. University of Illinois at Chicago. Vol.5 No.1: 74

Majid, N.W.A. (2015). Proses Perolehan Kompetensi Teknologi Informasi dan Komunikasi (TIK) dalam Program Praktik Industri Pada Industri Pasangan SMKN 2 Pengasih Kulon Progo. Tesis. Universitas Negeri Yogyakarta, Yogyakarta.

Majid, N.W.A, \& Sudira, P. (2017). Proses Perolehan Kompetensi Teknologi Informasi dan Komunikasi (TIK) Pada Industri 
Pasangan SMKN 2 Pengasih Kulon Progo. Jurnal Pendidikan Vokasi, 7(1), 14-29.

Martin, Florence. (2014). Use of Synchronous Virtual Classrooms: Why, Who, and How? MERLOT Journal of Online Learning and Teaching. 10( 2), 192-209

Motteram, G. (2001). The role of synchronous communication in fully distance education. Australian
Journal of Educational Technology, 17(2), 131-149.

Park, Y. J., \& Bonk, C. J. (2007). Is online life a breeze? A case study for promoting synchronous learning in a blended graduate course. MERLOT Journal of Online Learning and Teaching, 3(3), 307323. 